O MITO DA "IDEOLOGIA DE GÊNERO" NAS ESCOLAS: UMA ANÁLISE SOCIOLÓGICA DA TENTATIVA CONSERVADORA DE SILENCIAR O PENSAMENTO CRÍTICO

Rayane Dayse da Silva Oliveira

Erika Oliveira Maia Batalha

\title{
O MITO DA "IDEOLOGIA DE GÊNERO" NAS ESCOLAS: UMA ANÁLISE SOCIOLÓGICA DA TENTATIVA CONSERVADORA DE SILENCIAR O PENSAMENTO CRÍTICO
}

\section{THE MYTH OF "GENDER IDEOLOGY" IN THE SCHOOLS: A SOCIOLOGICAL ANALYSIS OF CONSERVATIVE ATTEMPT TO SILENCING CRITICAL THOUGHT}

Rayane Dayse da Silva Oliveira Erika Oliveira Maia Batalha

\section{RESUMO}

Este trabalho tem como objetivo discutir sobre a dita "ideologia de gênero", revelando o equívoco conceitual deste termo adotado pela classe conservadora, a fim de desqualificar a proposição do Plano Nacional de Educação de 2014, que sugere debates sobre desigualdades de gênero nas escolas. Nesse sentido, propomos uma desconstrução crítica do discurso político reacionário, mostrando que o conservadorismo, ao apoiar o afastamento desse debate, a partir da tentativa de deturpação da proposta do PNE, compreende por "ideologia de gênero" uma "doutrinação", fazendo uso do termo supracitado para acusar o pensamento crítico de agir de forma ideológica. Para efeito deste trabalho, utilizamos o conceito de ideologia, de Louis Althusser, que a compreende como uma representação da relação imaginária dos indivíduos com a sua condição de existência. O caráter imaginário fundamenta uma espécie de deformação que se pode observar em toda a ideologia, ou seja, a ideologia pode ser compreendida como um desconhecimento da realidade social e do que sustenta essa realidade. Portanto, compreendemos que 


\section{O MITO DA "IDEOLOGIA DE GÊNERO" NAS ESCOLAS: UMA ANÁLISE SOCIOLÓGICA DA TENTATIVA CONSERVADORA DE SILENCIAR O PENSAMENTO CRÍTICO \\ Rayane Dayse da Silva Oliveira \\ Erika Oliveira Maia Batalha}

a rejeição da discussão de gênero nas escolas, por parte de diversos representantes das câmaras municipais e das assembleias legislativas, sinaliza o apagamento de uma realidade existente de diversidade de gênero e sexualidade, onde a ausência de discussões causa danos irreversíveis como a prática do bullying. Essa ausência muito tem de ideológica, pois propõe a manutenção de uma ordem única e exalta a realidade como sendo natural, imutável e universal.

Palavras-chave: Ensino Médio. Ideologia. Gênero. Sociologia.

\section{ABSTRACT}

This paper aims to discuss the so-called "gender ideology", revealing the conceptual misconception of the adopted term by the conservative class in order to disqualify the proposal of the "Plano Nacional da Educação - 2014" (National Plan of Education 2014) which suggests debates about gender inequalities in schools. Accordingly, we propose a critical deconstruction of the reactionary political discourse, showing that the conservatism, by supporting the removal of that debate, from the PNE's attempted misrepresentation, understand by "gender ideology" a kind of "indoctrination", using the above term to accuse the critical thought to act in an ideological way. For purpose of this work we use the Louis Althusser's ideology concept, that understand it as a representation of imaginary relationship of the individuals with their existence condition. The imaginary aspect base a kind of deformation which could be observed on the whole ideology, that is, the ideology can be understood as an unfamiliarity of the social reality and what supports this reality. Therefore, we understand that the rejection of the gender discussion in schools, by various representatives of the city councils and legislative assemblies, signals the deletion of an existing reality of gender and sexuality diversity, where the absence of discussion causes irreversible damage such as bullying. This absence is very 
O MITO DA "IDEOLOGIA DE GÊNERO" NAS ESCOLAS: UMA ANÁLISE SOCIOLÓGICA DA TENTATIVA CONSERVADORA DE SILENCIAR O PENSAMENTO CRÍTICO

Rayane Dayse da Silva Oliveira

Erika Oliveira Maia Batalha

ideological, because proposes the upkeep of a single order and exalts reality as natural, immutable and universal.

Keywords: High School. Ideology. Gender. Sociology.

\section{INTRODUÇÃO}

Tendo como ponto de partida as recentes propostas de censura a professores através de projetos como, no âmbito nacional, a "Escola sem partido" (Projeto de Lei 193/2016 de autoria do Senador Magno Malta do PR-ES), que tenta incluir na Lei de Diretrizes e Bases da Educação Nacional uma obrigatoriedade de neutralidade absoluta dos professores, tentando resumir sua tarefa a uma mera reprodução de conteúdos sem nenhuma problematização ou leitura crítica do que está apresentando e, no âmbito estadual, o Projeto de Lei 1411/2015 (de autoria do deputado federal Rogério Marinho do PSDB-RN) que, na mesma linha e com inspiração no primeiro, versa sobre a tipificação do crime de "Assédio Ideológico", na tentativa de proibir a livre expressão dos professores em sala de aula, nomeando de "doutrinação ideológica" qualquer posicionamento crítico ante as estruturas sociais dominantes de classe, gênero, etnia, religião e etc. Num plano mais amplo traçamos uma discussão mais geral e informativa sobre essas propostas para que seja possível, na sequência, debater a questão mais específica, e, que é o objetivo principal do artigo, da dita "ideologia de gênero", problematizando-a e discutindo o que a referida proposta pode acarretar.

Para que seja possível desenvolver essa proposta, dividimos o trabalho em quatro momentos, no primeiro, discorremos sobre os respectivos projetos, o primeiro, o projeto de lei do senado $n^{0}$ 193, de 2016 de autoria do Senador Magno Malta e o segundo a PL 1411 de 2015 com idealização do Deputado Rogério Marinho. No segundo ponto abordamos o conceito de ideologia com base em Louis 
O MITO DA "IDEOLOGIA DE GÊNERO" NAS ESCOLAS: UMA ANÁLISE SOCIOLÓGICA DA TENTATIVA CONSERVADORA DE SILENCIAR O PENSAMENTO CRÍTICO

Rayane Dayse da Silva Oliveira

Erika Oliveira Maia Batalha

Althusser. O terceiro momento discutimos de forma crítica a chamada ideologia de gênero de gênero, baseado nos estudos críticos de gênero e sexualidade. E por fim, sinalizamos possíveis conclusões dessa discussão. Utilizamos como referencial teórico para fundamentar a discussão autores como Pierre Bourdieu, Joan Scott e Guacira Lopes Louro, além de Louis Althusser.

\section{O PROGRAMA ESCOLA SEM PARTIDO E A PL 1411/2015}

O projeto escola sem partido tem origem em 2004, mas somente ganha força e forte adesão a partir do ano de 2015, ano em que começou a ser sistematizado mais efetivamente. O projeto de âmbito nacional inspirou a criação de vários outros, na mesma linha, em âmbitos estaduais. É importante compreender que este projeto deturpa a perspectiva de "liberdade" tendo em vista que é uma lei contrária a um suposto abuso de ensinar, tendo como objetivo a fixação de cartazes nas salas de aula do ensino fundamental e médio com ditos deveres que o professor deve seguir. Vejamos, por exemplo, o ponto 1 do cartaz, que afirma "O professor não se aproveitará da audiência cativa dos alunos para promover os seus próprios interesses, opiniões, concepções, ou preferências ideológicas, religiosas, poltíticas e partidárias". Ao que pode parecer a olho nu, algo da ordem da imparcialidade, indica na verdade o apagamento de uma liberdade possível da sala de aula como um âmbito criativo, que fomenta discussões e proporciona debates. A proposição da escola sem partido nada mais é do que uma reação ao pânico da classe política conservadora que teme a realidade social em suas múltiplas possibilidades culturais, religiosas, de gênero e sexualidade e com isso, traveste suas crenças em projetos de lei.

Esse projeto motivou vários outros em âmbito estadual, neste trabalho especificamente, vamos discorrer sobre o projeto de lei que criminaliza o nomeado "assédio ideológico" supostamente praticado por professores no âmbito escolar. 


\section{O MITO DA "IDEOLOGIA DE GÊNERO" NAS ESCOLAS: UMA ANÁLISE SOCIOLÓGICA DA TENTATIVA CONSERVADORA DE SILENCIAR O PENSAMENTO CRÍTICO \\ Rayane Dayse da Silva Oliveira \\ Erika Oliveira Maia Batalha}

Esse projeto, se assemelha bastante ao do Senador Malta, no entanto, pretendemos discorrer sobre o segundo de forma mais detalhada.

No referido projeto o deputado Rogério Marinho expõe o que ele compreende por "Assédio ideológico", "Entende-se como Assédio Ideológico toda prática que condicione o aluno a adotar determinado posicionamento político, partidário, ideológico ou qualquer tipo de constrangimento causado por outrem ao aluno por adotar posicionamento diverso do seu, independente de quem seja o agente, notase a partir do exposto que o referido deputado conceitua a perspectiva de ideologia longe de qualquer embasamento teórico, e ainda se situa em um contexto alheio a realidade do nosso ensino.

O desconhecimento não para por aí, a justificativa desse projeto de lei se baseia especificamente em na exposição de fragmentos retirados de documentos sem fonte, do Partido dos Trabalhadores, nesse aspecto, identificamos o delírio odioso em torno do PT, e o que aos olhos dos conservadores representa a direita brasileira. É importante destacar que a direita brasileira não se restringe ao Partido dos Trabalhadores. $O$ deputado chama as ideias retiradas dos documentos um ato de autoritarismo, vejamos como o deputado conduz sua "análise". Rogério Marinho afirma, referindo ao PT e à suposta "ideologia de gênero que exala quase que naturalmente desse partido em específico": "Para eles, é preciso calar a pluralidade, a dúvida saudável e substituir a linguagem, criando um ambiente onde proliferam mitos, inversões, clichês, destruição de reputações e conflitos desnecessários" e continua, "Para o totalitarismo vingar, é preciso destruir a coesão social e as tradições da sociedade". Alguns pontos podem ser destacados na citação do deputado, o primeiro é que há uma deturpação da escola como espaço aberto e livre, que estimula a discussão de temas diversos para a venda da ideia de que uma escola crítica de paradigmas de ordem sociais instituídas seria uma escola de doutrinação. Isso se deve a um verdadeiro pânico em torno da desconstrução de alguns paradigmas tomados como ideais, por exemplo, da religião cristã 
O MITO DA "IDEOLOGIA DE GÊNERO" NAS ESCOLAS: UMA ANÁLISE SOCIOLÓGICA DA TENTATIVA CONSERVADORA DE SILENCIAR O PENSAMENTO CRÍTICO

Rayane Dayse da Silva Oliveira

Erika Oliveira Maia Batalha

hegemônica, que estabelece consequentemente, o rompimento de hierarquias e privilégios.

Outro ponto de que Marinho fala é o da destruição das tradições, essas tradições longe de serem as verdades absolutas, são ideológicas a partir do que Althusser designa por ideologia que são "[...]o sistema das ideias, das representações, que domina espírito de um homem ou de um grupo social" (ALTHUSSER, 1990, p.69). Nesse aspecto, a manutenção de uma tradição é algo tão ideológico quanto a imposição de outra lógica ideológica. O não ideológico seria desconstruir o caráter imutável das coisas, impulsionando a percepção crítica de uma realidade.

De acordo com o pesquisador Alípio Sousa Filho as "transgressões" são este o processo pelo qual é possível romper com a realidade instituída que geralmente se materializam por reivindicações para mudanças sociais. "Potência transgressiva, resistência às inércias e aos constrangimentos sociais, que esvaziam todas as pretensões de uniformização e obediência mantidas pelos gestores da vida social" (SOUSA FILHO, 2009, p. 15). A partir disso, o espaço escolar como motivador crítico que potencializa o rompimento com a lógica normativa, lógica essa que estabelece hierarquias, exclusões e mantém privilégios a poucos, acaba por danificar o conservadorismo tanto religioso, como machista, racista e classista, com isso, verificamos que os projetos que propõem o limite da liberdade do professor ilustram o pânico em torno de possíveis mudanças dessas instituições.

\section{O QUE DE FATO É IDEOLOGIA?}

O sentido que o conceito de ideologia tem nas ciências humanas possui um caráter totalmente adverso daquele empregado no seu uso comum. Ideologia longe de ser um conjunto de ideias ou ideais e visões de mundo, é, na verdade, um mecanismo de reprodução da dominação por meio do qual o que é o construído é 


\section{O MITO DA "IDEOLOGIA DE GÊNERO" NAS ESCOLAS: UMA ANÁLISE SOCIOLÓGICA DA TENTATIVA CONSERVADORA DE SILENCIAR O PENSAMENTO CRÍTICO \\ Rayane Dayse da Silva Oliveira \\ Erika Oliveira Maia Batalha}

posto como natural, imutável e a-histórico. A ideologia é como uma nata, que cobre o caráter histórico e social das coisas, é um mascaramento da realidade social através do qual a aparência aparece como essência natural e imutável à que se deve apenas aceitar e seguir sem questionar, ela funciona, portanto como um apagamento do caráter de constructo da realidade social, colocando esta como existindo naturalmente e por si mesma sem a agencia dos indivíduos. Essa conceituação tem como base a definição pós-marxista de ideologia que é sintetizada com notável riqueza de ideias por SOUSA FILHO (2016, pg. 01) que pontua: "Adquirindo, principalmente, uma ilusória aparência de realidade por si mesma, eterna e universal, pelas muitas maneiras que "ilusões" ("ilusão de uma época", "ilusão política", "ilusão religiosa") tornam-se as formas de sua explicação e representação".

A ideologia está presente em todas as esferas sociais, dentre elas: a escola. A escola é um dos espaços onde há maior índice de "conservação social" conceito apresentado por BOURDIEU (1999) em "A escola conservadora: as desigualdades frente à escola e à cultura" é nela que os sujeitos em construção passam maior parte do tempo e onde interiorizam e reproduzem os conceitos dominantes da sociedade. Considerando o seu peso na trajetória dos indivíduos a escola é vista também como detentora de um grande potencial transformador, no entanto, não é fácil conseguir implementar qualquer que seja a mudança dentro da escola, na maior parte das vezes a mudança é impedida, através, principalmente, da proibição do debate. Tudo o que questiona a ordem dominante é colocado na pauta de "temas polêmicos", e, por sua vez, silenciado. Os temas considerados polêmicos o são porque atingem diretamente a ideologia, ou seja, desmascaram questões sociais postas como naturais, desvelando o seu caráter de construto, de obra humana, o que pode ser extremamente prejudicial à classe dominadora, esta não quer revolta, quer sujeitos alienados, cúmplices e legitimadores da sua própria dominação, em beneficio, é claro, dela própria e dos seus privilégios. 


\section{O MITO DA "IDEOLOGIA DE GÊNERO" NAS ESCOLAS: UMA ANÁLISE SOCIOLÓGICA DA TENTATIVA CONSERVADORA DE SILENCIAR O PENSAMENTO CRÍTICO \\ Rayane Dayse da Silva Oliveira \\ Erika Oliveira Maia Batalha}

Apesar da resistência, o enfrentamento ao conservadorismo vem sendo travado e obtido relativo sucesso. Cada vez mais tenta se implementar a crítica, sempre que possível, às estruturas que se mostram problemáticas em nossa sociedade. Em contrapartida, para combater essa tendência à transformação social que felizmente vem crescendo nos últimos anos, recentemente tem emergido uma onda conservadora que declarou verdadeira guerra ao pensamento crítico e tem trabalhado fortemente contra ele.

Acusando professores de doutrinadores e assediadores ideológicos, representantes políticos, sobretudo com declarada convicção religiosa, vêm propondo leis para criminalizar professores que abordem com um posicionamento crítico os conteúdos que ministra em sala de aula. A ideia de acusar de "doutrinação ideológica" professores que trazem o debate e o pensamento crítico para a sala de aula, revela, ela própria, que o caráter ideológico não está no questionador, no caso o professor, mas no que não permite ser questionado. A tentativa de calar professores, impedir o debate e impedir que se mostre uma outra visão sobre as coisas revela o caráter ideológico da escola e dos proponentes dessas leis, que tentam desesperadamente manter a ordem social atual, querendo estabelecê-la como única e pior, como inquestionável, propondo punir até criminalmente quem se atreva a questioná-la. Para isso usa de artifícios como esse de tentar chamar de ideologia aquilo que é o seu oposto, aquilo que é ela própria quem faz.

Em suma, a ideologia longe de ser a tentativa de mudança é, ao contrário, tudo o que se faz para a manutenção de uma ordem única, ordem esta que oculta elementos da realidade e apaga a agência do sujeito na construção histórica e social do mundo, mostrando apenas uma falsa aparência das coisas dentro do limite do que é permitido mostrar sem que se gere revolta. Os professores que tentam educar para a criticidade são atacados justamente porque o senso crítico é um perigo para a ordem dominante. Afinal uma sociedade de sujeitos críticos representa o próprio declínio desta ordem, uma vez que estes não aceitariam com tanta passividade todos os retrocessos absurdos perpetrados contra eles próprios diariamente. Desse 
O MITO DA "IDEOLOGIA DE GÊNERO" NAS ESCOLAS: UMA ANÁLISE SOCIOLÓGICA DA TENTATIVA CONSERVADORA DE SILENCIAR O PENSAMENTO CRÍTICO

Rayane Dayse da Silva Oliveira

Erika Oliveira Maia Batalha

modo, fica explícita qual a verdadeira intenção desses projetos referentes à suposta ideologia nas escolas, que é o de podamento da escola como possibilidade crítica, e ainda, mascaramento da realidade manutenção de uma ordem instituída.

\section{A "IDEOLOGIA DE GÊNERO" NAS ESCOLAS}

A chamada "ideologia de gênero" emergiu a partir do projeto de lei do deputado Eros Biondini em 2015, que dispõe pela proibição da discussão de gênero nas escolas, proposta no Plano Nacional de Educação de 2014. A proposta do PNE propõe a inserção da discussão de igualdade de gênero em escolas do ensino fundamental e médio e foi vetada a nível municipal e estadual. Essa exclusão significa enorme retrocesso e nos mostra claramente o caráter ideológico presente nessa tentativa de manter uma ordem única das coisas através da censura proposta no impedimento de que tal questão seja problematizada e apresentada sobre outras perspectivas na sala de aula.

Diversos teóricos discorrem sobre as hierarquias de gênero em nossa sociedade, os primeiros estudos que discutem o conceito de gênero foram encabeçados por autoras como Rubin (1975) e Scott (2009), que buscavam compreender as situações de opressão sofridas pelas mulheres. As teorias de gênero impulsionaram as discussões sobre a diferenciação entre sexo e gênero, a compreensão dessas categorias como construções sociais, permitindo distinções entre as dimensões biológicas e social.

Nesse aspecto, é necessário compreender que as relações de gênero socialmente construídas produzem desigualdade de poder, "Desta forma, as relações de gênero produzem uma distribuição desigual de poder, autoridade e prestígio entre as pessoas de acordo com o seu sexo. É por isso que se diz que as relações de gênero são relações de poder" (GOUVEIA \& CAMURÇA, 1997, p. 08). 


\section{O MITO DA "IDEOLOGIA DE GÊNERO" NAS ESCOLAS: UMA ANÁLISE SOCIOLÓGICA DA TENTATIVA CONSERVADORA DE SILENCIAR O PENSAMENTO CRÍTICO \\ Rayane Dayse da Silva Oliveira \\ Erika Oliveira Maia Batalha}

Essas determinações de hierarquias longe de ter relação com a natureza são invenções socialmente construídas e produzem, consequentemente, privilégios. A apreensão desses valores e normas produzem diferenças e desvantagens para aqueles que não se encontram no topo da ordem de hierarquia, no caso, as mulheres, as pessoas trans e outros que não se enquadram no modelo normativo patriarcal.

Joan Scott conceitua gênero como "[...] um elemento constitutivo das relações sociais, fundadas sobre as diferenças percebidas entre os sexos, e o gênero é um primeiro modo de dar significado às relações de poder" (SCOTT, 1990, p. 14). Nesse aspecto, a relação do gênero com o sexo acaba fornecendo o caráter de naturalização dos comportamentos e consequentemente a naturalização da dominação masculina. Scott argumenta ainda que é necessário desconstruir o caráter de oposição binária "masculino e feminino", pois estes supõem naturalidade de superioridade de um grupo a outro. A lógica binária fornece elementos que apontam para um lugar fixo e natural de cada gênero.

Guacira Lopes Louro, teórica pós-estruturalista, discorre sobre a questão do gênero na educação e ressalta a necessidade de pensar as desigualdades de gênero a partir do aspecto social: "As justificativas para as desigualdades precisariam ser buscadas não nas diferenças biológicas (se é que mesmo essas podem ser compreendidas fora de sua constituição social), mas sim nos arranjos sociais, na história, nas condições de acesso aos recursos da sociedade, nas formas de representação" (LOURO, 2007, p. 22).

A desconstrução social do padrão binário permite, nesse sentido, romper com hierarquias e privilégios "A desconstrução trabalha contra essa lógica, faz perceber que a oposição é construída e não inerente e fixa. [...] Supõe que se historicize a polaridade e a hierarquia nela implícita (LOURO, 2007, p. 32). Esses padrões e papéis instituídos só têm êxito a partir do processo ideológico, ou seja, para a manutenção dessa ordem se faz necessária a ideologia, uma vez que ela "[...] assegura a coesão social, regulando os vínculos que unem os indivíduos às normas 


\section{O MITO DA "IDEOLOGIA DE GÊNERO" NAS ESCOLAS: UMA ANÁLISE SOCIOLÓGICA DA TENTATIVA CONSERVADORA DE SILENCIAR O PENSAMENTO CRÍTICO \\ Rayane Dayse da Silva Oliveira \\ Erika Oliveira Maia Batalha}

e aos papéis que the são atribuídos (SOUSA FILHO, 2016, p. 03). A ideologia assegura que os papéis sejam cumpridos sem grandes questionamentos. $O$ pesquisador Sousa Filho (2016) afirma que a ideologia se baseia no desconhecimento, sendo a partir do desconhecimento que se naturaliza e se estabelece a ordem instituída.

Entende-se que a conservação da ordem social é realizada a partir de um contexto simbólico, conforme Bourdieu afirma, a escola é um dos meios pelos quais se ratifica a instituição social, é nela que se legitima as desigualdades e as caracteriza como naturais (BOURDIEU, 1999, p. 41). Embora a ideologia compreenda um processo de reiteração dos padrões e da conservação social, é possível pensar as resistências, as transgressões dessa ordem instituída. Os indivíduos, embora sob o domínio do discurso ideológico, reinterpretam e resinificam a realidade, tornam-se pontos de resistência às ideias e às instituições sociais dominantes que representam controle, sujeição, dominação, enquanto realizadoras da moralidade aceita, de padrões culturais, estruturas sociais (SOUSA FILHO, 2012, p.12).

Compreendemos então a ideologia como um processo de instituição de padrões sociais que são tomados como dados da natureza, imutáveis e universais, nesse aspecto, compreendemos também que a chamada "ideologia de gênero" emerge como deturpação do que na realidade seria ampliar a discussão da diversidade de gênero nas escolas e consequentemente desconstruir padrões que estabelecem desigualdades, mantém privilégios e promove exclusões. O objetivo de projetos como o da "ideologia de gênero" é uma reação de pânico conservador a uma resposta de resistência, de subversão de uma ideologia baseada em um contexto tradicionalista.

O seguinte texto retirado do projeto de "ideologia de gênero" ilustra o pavor em torno de uma discussão crítica sobre as instituições tradicionais, e ainda, elege um comportamento, uma sexualidade normal e nega a potencialidade crítica de estudantes os colocando como sujeitos passivos ou meros fantoches: "Não cabe à 


\section{O MITO DA "IDEOLOGIA DE GÊNERO" NAS ESCOLAS: UMA ANÁLISE SOCIOLÓGICA DA TENTATIVA CONSERVADORA DE SILENCIAR O PENSAMENTO CRÍTICO \\ Rayane Dayse da Silva Oliveira \\ Erika Oliveira Maia Batalha}

escola doutrinar sexualmente as crianças, desprovidas que são das necessárias compreensão e maturidade, ainda mais quando essa doutrina vai contra todo o comportamento habitual e majoritário da sociedade, pois isso pode causar-Ihes danos irreversíveis quanto à sexualidade e quanto a aspectos psicológicos".

Esse texto mostra não só o pânico quanto à discussão das questões de gênero na escola, como evidencia também a ignorância de quem o escreveu, fica claro que esse sujeito não sabe o que é gênero e muito menos sexualidade. $E$ que não nos enganemos, o autor desse projeto não representa um caso isolado, mas é a síntese da voz da maioria dos sujeitos de nossa sociedade, que cegos pela intolerância e ignorância, lutam para manter a cultura estática, congelada e vertical.

Os proponentes de tais projetos, mal informados e/ou agindo de má fé, não conseguem compreender que o que nós educadores estamos dizendo é que os gêneros são construtos e, como construção social e cultural que são, possuem hierarquias e dominâncias estabelecidas historicamente e, que, por se mostrarem problemáticas devem ser desconstruídas, e essa desconstrução só pode ser viabilizada através da educação e da informação. Na contramão dessa perspectiva, parecem acreditar que isso sinaliza, na verdade, uma catástrofe, o fim da familia, dos valores tradicionais e a longo prazo até da extinção da espécie, fatos que supostamente serão todos desencadeados a partir do debate de gênero nas escolas.

$\mathrm{Na}$ perspectiva limitada desses sujeitos, os professores, munidos dessa suposta "ideologia de gênero" (que, segundo eles, é o conjunto de ideias que define o gênero como uma escolha, livre de qualquer condicionamento não só biológico como também social ou cultural) irão ensinar às crianças que gêneros não sendo uma determinação biológica, podem ser escolhidos livremente e que a partir daquele momento eles estão livres para "escolher" ser do outro sexo, se assim o quiserem. Defendem, portanto, a ideia de que a discussão de gênero significa necessariamente ensinar crianças a serem gays, já que para eles sexo/gênero/sexualidade são uma "sequência compulsória" (BUTLER, 2010) e 


\section{O MITO DA "IDEOLOGIA DE GÊNERO" NAS ESCOLAS: UMA ANÁLISE SOCIOLÓGICA DA TENTATIVA CONSERVADORA DE SILENCIAR O PENSAMENTO CRÍTICO \\ Rayane Dayse da Silva Oliveira \\ Erika Oliveira Maia Batalha}

mostrar o caráter de constructo dos papéis sociais implica em modificar a base inicial dessa sequência, quebrando, por conseguinte todo o resto.

O que não é compreendido é que quando dizemos que os gêneros são um constructo social e histórico, não estamos negando a existência de um corpo genitalizado, estamos apenas dizendo que esse genital não é o que determina a identidade dos sujeitos, nem muito menos é o que define o que significa ser mulher ou homem e o que pertence a cada um desses gêneros, afinal essa significação é cultural e, portanto, variante. O que designa os gêneros são as significações sociais dadas aos corpos, são estas significações que atribuem os papéis e lugares sociais de cada um deles e não um condicionamento inato determinado pelos órgãos genitais. O problema disso tudo e que é também o que tentamos desconstruir reside no fato de que essa definição social dos papéis e significações de gênero se dão de maneira verticalizada sendo assim hierárquica, dessa maneira acaba sendo a origem de todas as violências e dominações decorrem dela e que se apresentam cotidianamente em nossa sociedade.

Colocar as crianças em contato com essa discussão tem, portanto, a finalidade de tentar desconstruir as violências de gênero, mas essa tentativa de trabalhar a temática da igualdade foi deturpada e colocada como sinônimo de "doutrinação sexual", leia-se "doutrinação para a homossexualidade", uma vez que o que a ordem dominante considera como doutrinação é apenas aquilo que questiona a ordem única e estabelecida em nossa sociedade, que é, como sabemos, heteronormativa. Dessa maneira, os principais argumentos desse tipo de projeto de lei que estamos problematizando, giram em torno da ideia de que trabalhar os problemas de gênero em sala significa a mesma coisa que fazer uma espécie de propaganda da homossexualidade e doutrinar crianças para ela. Diante disso, além de encontramos essa barreira temos que lidar ainda com o fato de que os desavisados que ouvem tais absurdos de líderes políticos, que são pessoas formadoras de opinião, acabam por considerar essas ideias como legítimas e odiar e 
O MITO DA "IDEOLOGIA DE GÊNERO" NAS ESCOLAS: UMA ANÁLISE SOCIOLÓGICA DA TENTATIVA CONSERVADORA DE SILENCIAR O PENSAMENTO CRÍTICO

Rayane Dayse da Silva Oliveira

Erika Oliveira Maia Batalha

lutar contra o que sequer compreendem, corroborando assim com uma maior resistência a essa mudança no âmbito social.

\section{CONCLUSÕES}

Levando em consideração todos os aspectos referentes à ideologia abordados e analisados neste artigo, é importante que fique a compreensão de que projetos como "Escola sem partido" e "Ideologia de gênero" sinalizam retrocesso significativo para o sistema de educação, uma vez que tentam limitar a liberdade e crítica no contexto de formação, e ainda, pretendem reiterar valores tradicionais que expõe determinados grupos a situação de exclusão. A inserção de uma formação crítica no contexto da escola visa desconstruir aspectos ideológicos nocivos, consequência disso, a ala política conservadora reage na tentativa de deturpar a iniciativa do Plano Nacional de Educação de 2015, bem como a sugestão de discussão de gênero e sexualidade, denominando-a de ideologia de gênero, quando na verdade, a ideologia é justamente o processo de desconhecimento de outras realidades para além da instituída. A iniciativa do PNE funcionaria como uma alternativa crítica ao contexto machista, heteronormativo excludente, trazendo discussões no âmbito da diversidade sexual e de gênero.

Fica claro no decorrer do artigo que projetos como os que foram apresentados são reações a possíveis subversões de uma ordem, o que causa a classe conservadora pânico, pois esta perderia seus privilégios e ainda, não teria como justificar suas aversões ao diferente. Outro ponto bastante significativo é pensar como urgente a discussão de gênero e sexualidade nas escolas, tendo em vista, por exemplo, que minimizaria os frequentes atos de violência que ocorrem em âmbito escolar destinados aqueles que diferem da norma. Por fim, ainda refletimos que os autores dos projetos de lei apresentados têm vínculo direto com igreja e utilizam de argumentos que se baseiam em uma norma natural, imutável e divina, o 


\section{O MITO DA "IDEOLOGIA DE GÊNERO" NAS ESCOLAS: UMA ANÁLISE SOCIOLÓGICA DA TENTATIVA CONSERVADORA DE SILENCIAR O PENSAMENTO CRÍTICO \\ Rayane Dayse da Silva Oliveira \\ Erika Oliveira Maia Batalha}

que nesse aspecto deve ser pensado com senso crítico, tendo em vista que o Estado é laico e que, consequentemente, questões que decidem a formação de crianças e adolescentes não podem ser pensadas com base em dogmas religiosos.

Nesse aspecto, é importante, por fim, compreender que a ideologia é construída social e culturalmente e reiterada por normas, padrões a partir do simbólico e que ela não pode ser tomada como algo que é da ordem do imutável, mas tem que ser percebida na possibilidade de resistência, de subversão. Reafirmamos, a partir disso, que a perspectiva crítica na formação escolar é uma alternativa para minimizar as desigualdades, as opressões, as exclusões, e as violências sofridas pelos que não estão inseridos na norma.

\section{REFERÊNCIAS}

ALTHUSSER, Louis. Ideologia e aparelhos ideológicos do estado. Lisboa: Presença, 1974.

BOURDIEU, P. A escola conservadora: As desigualdades frente à escola e à cultura. In. NOGUEIRA, M. A.; CATANI, A. Escritos de educação. 2ed. Petrópolis: Vozes, 1999.

BUTLER, Judith. Problemas de Gênero: Feminismo e subversão da identidade. Tradução Renato Aguiar. 3. ed. Rio de Janeiro: Civilização Brasileira, 2010.

ESPÍRITO SANTO. Assembleia Legislativa. Projeto de Lei do Senado PLS no 193/2016. Inclui entre as diretrizes e bases da educação nacional, de que trata a Lei ํo 9.394, de 20 de dezembro de 1996, o "Programa Escola sem Partido". Disponível em: <https://www25.senado.leg.br/web/atividade/materias/-/materia/125666>. Acesso em 27 de outubro de 2016. Texto Original.

GOUVEIA, T. \& Camurça, S. O que é gênero. Cadernos SOS Corpo Gênero e Cidadania, Recife: SOS Corpo, 1997.

LOURO, Guacira Lopes. Gênero, Sexualidade e Educação: uma perspectiva pósestruturalista. 9. ed. Petrópolis, RJ: Vozes, 2007. 


\section{O MITO DA "IDEOLOGIA DE GÊNERO" NAS ESCOLAS: UMA ANÁLISE SOCIOLÓGICA DA TENTATIVA CONSERVADORA DE SILENCIAR O PENSAMENTO CRÍTICO \\ Rayane Dayse da Silva Oliveira \\ Erika Oliveira Maia Batalha}

RIO GRANDE DO NORTE. Assembleia Legislativa. Projeto de Lei PL 1411/2015. Altera o Decreto-lei no 2.848, de 1940 e a Lei no 8.069, de 1990. Tipifica o crime de Assédio ldeológico e dá outras providências. Disponível em: <http://www.camara.gov.br/proposicoesWeb/fichadetramitacao?idProposicao= 1229808>. Acesso em 27 de outubro de 2016. Texto Original.

SCOTT, Joan W. Gênero: Uma Categoria Útil para a Análise Histórica. Traduzido pela SOS: Corpo e Cidadania. Recife, 1990.

SOUSA FILHO, Alípio. Cultura, Ideologia e Representações in: O Que é Ideologia? A Conceituação Pós-Marxista. 1ed. Maputo: Escolar Editora, v.19. 2016.

Mito e ldeologia. Comunicologia (Brasilia), v.01, 2006.

. Ideologia e Transgressão. Revista Electrónica de

Psicología Política (En línea), v. 11, p. 207-224. 2012. 